\title{
UMBRELLA: Using MicroBes for the REgulation of heavy metaL mobiLity at ecosystem and landscape scAle
}

\author{
Erika Kothe • Georg Büchel
}

Received: 13 February 2014 / Accepted: 19 February 2014 / Published online: 25 March 2014

(C) Springer-Verlag Berlin Heidelberg 2014

Keywords Acid mine drainage $\cdot$ Microbially aided phytoremediation $\cdot$ Biomineralization $\cdot$ Metal mobility . Landscape metal distribution modeling $\cdot$ Guidelines

This special issue focuses on metal-contaminated areas resulting from mining activities. These sites are characterized by low nutrient availability, poor soil quality, and low $\mathrm{pH}$, in addition to high metal loads. The contamination at former mining sites most often is associated with acid mine drainage leading to the dispersal of metals. The resulting areas are compromised with respect to both use of land for, e.g., agronomy and forestry, and groundwater, the main source of drinking water, restricting future use. In addition, the contamination can spread, if not attended to, contaminating additional, previously non-contaminated ecosystems. Government regulations for effective management of contaminated sites exist worldover, and reclamation of acid mine drainage-influenced areas attracts growing interest. Remediation actions are necessary, which, in addition to geo-engineering strategies, increasingly include monitored natural attenuation and bioremediation. This needs to be based on a detailed understanding of processes in bio-geo interactions at metal-contaminated sites, which is addressed here to provide an integrated approach summarized in a scheme for useful application of each of these remediation actions shown in this special issue at a generalized former mining site. The proposed applications help to minimize the risk to human health and environmental impact and are cost-efficient.

Responsible editor: Philippe Garrigues

E. Kothe $(\bowtie)$

Institute of Microbiology, Friedrich Schiller University of Jena,

Neugasse 25, 07743 Jena, Germany

e-mail: erika.kothe@uni-jena.de

G. Büchel

Institute of Geosciences, Friedrich Schiller University of Jena,

Burgweg 11, 07749 Jena, Germany
Soil is the basis of terrestrial life and has a major impact on human life through its use for agriculture, forestry, or general land use. In addition, it remains the largest terrestrial ecosystem that is shaped by high numbers of microorganisms and plant roots. The metabolic activities of both microorganisms and plants sustain pedogenesis which, however, differs with respect not only to base rock material and climatic conditions, but also to, e.g., pollution. Root exudates as well as microbiological acidification and release of chelating agents take part in heavy metal mobilization and immobilization processes, which are of high impact at metal-rich sites. The ecotoxicologically relevant heavy metal concentrations are dependent on interaction with soil particles and microbial surfaces; hence, inoculation strategies may improve future land use.

Mobilization and distribution pathways for metals from source, where geo-engineering techniques may be deployed, to sink need to be re-evaluated. Nature has evolved ecosystems able to cope with high metal loads, and by learning from the evolutionary and biological processes, it may be feasible to adopt additional strategies for bioremediation. During natural attenuation, new minerals can be formed. This might lead to supergenic ore formation and hence provides means to even use these metals without disturbing new, natural sites. In this special issue, we will discuss all mentioned mobilization and immobilization mechanisms to contribute to a general understanding of bioremediation potentials. Thus, we may draw on the potential of natural attenuation instead of premature application of high-cost geo-engineering, depending on sitespecific parameters. This concept will allow for the reduction of the costs of an estimated 38 billion Euro per year incurred by society at large for soil destruction and environmental degradation.

The formation of acid mine drainage (AMD) or also of acid rock drainage (ARD) is a process related to unearthing metal ores, many of which are sulfidic ores. Similar processes leading to AMD apply to coal mining, since coal also contains sulfur in pyrite and marcasite as well as organically bound sulfur. The anoxic environment in the mine does provide 
protection against sulfide oxidation, but after mining, exposure to oxygen and water generates sulfuric acid, and the acidic conditions lead to high metal solubility. A good example is the Rio Tinto area (Rull et al. 2014). The end product is the formation of iron (hydro)oxides. However, not only iron is depositing as a (hydro)oxide. Depending on the co-occurring metals, manganese and aluminum (hydro)oxides may be deposited. The precipitation of metal (hydro)oxides leads to co-precipitation and adsorption of other metals. Recrystallization of the hydroxide minerals in sediments can lead to long-term stabilization. The different affinity of metals to these precipitates may lead to fractionation which has been used, e.g., in rare earth element pattern studies, to determine source and sink relationships and to identify processes involved in metal distribution throughout the environment (Grawunder et al. 2014).

Plant roots that come into contact with hardpans of metal (hydro)oxides are prone to receive high metal loads with their water uptake (Langella et al. 2014). Since the metals are soluble in water, the plants experience phytotoxic metal concentrations in roots and also in aboveground plant tissues. Hence, plant growth is impacted at metalliferous AMD sites. The same, of course, holds true for microbiology: bacteria or fungi at these sites need to express resistance mechanisms for survival (Sprocati et al. 2014a, b).

One option of coping with an AMD site is to set it apart for nature conservancy. This has been the case with, e.g., parts of the Rio Tinto area, Spain, and with Parys Mountain in Wales, UK. The disturbance of an ecosystem, at least at intermediate levels, leads to an increase in species richness; therefore, sites impacted by a heterogeneous and widespread source of contaminant, as prevalent in AMD, might find an increase in species. However, if the metal burden gets too high, bare land will be visible, and species number decreases, as many species will no longer be able to cope with the harsh environment. From such a disturbed site, a secondary succession will start forming a new habitat eventually. On such disturbed sites, a specialized flora and microflora develop over time. The plants must be able to cope with the high metal contents (Wernitznig et al. 2014). This process can be enhanced by mycorrhizae which work as biofilters and hence can protect plants from excess uptake of metals. The examples that can be taken from understanding the natural succession might be useful to develop strategies which speed up desired processes (Neagoe et al. 2014). The metal uptake into fungi and plants thus needs investigation to understand mechanisms that may be useful in bioremediation (Baumann et al. 2014). In creeks, natural attenuation often is seen to lower the burden of mobile metals already in comparatively short distances from the AMD entrance (Podda et al. 2014; Medas et al. 2014). Natural attenuation, however, rarely is the single solution to AMD since a rainstorm will (re)mobilize the precipitates. Aside from testing plant fitness and growth under metal-rich conditions for each given soil, soil microbiology is important and should be included in any strategy aiming at revegetation of metalcontaminated soil (Nicoară et al. 2014). Speeding up processes will rely on amendments with microbial strains and planting of species able to cope with metal-rich environments. The specific changes to the environment can be made visible by, e.g., isotope studies (Pérez Rodríguez et al. 2014).

Plant roots stabilize and protect soil from wind and water erosion. Decaying plant roots leave passages also allowing for preferential water flow. Furthermore, living roots contain special tissues for aeration and therefore improve oxygen availability for microorganisms in soil. At the same time, up to $30 \%$ of plant net photosynthesis products can be excreted by the roots; these root exudates consist mainly of organic acids like acetate, oxalate, malate, and citrate. These provide nutrition for soil microorganisms which multiply in the vicinity of roots. This rhizosphere thus is of special importance for pedogenesis, soil structure, and soil function. In addition, this is the place where interactions with metals can lead to uptake of metals into biomass.

Plants can be used to extract metals from soil. The harvested plant material then may be burnt under supervised conditions, and the ashes may be deposited safely or even be used for metal recovery, then called phytomining. However, plants also can be used in an approach called phytostabilization, in which uptake into aboveground biomass is minimized. This material is, e.g., useful for energy plant production, and hence makes future land use possible at sites where the pollution is not removed, but bound into mineral phases that prevent further distribution. The soil conditions, microbial additions,

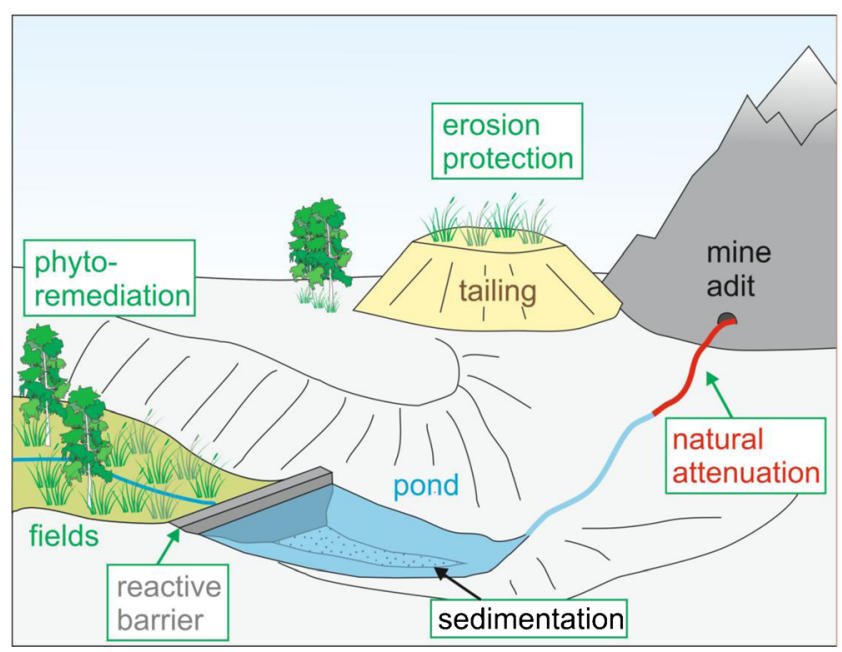

Fig. 1 Conceptual drawing combining measures of integrated management of AMD sites 
and plant choice are decisive factors determining whether metal uptake or exclusion prevails (Sjöberg et al. 2014).

Until recently, industries attempting restoration did not recognize that plants require appropriate belowground ecosystems, especially at acutely challenging sites. The establishment of the vegetation and its survival under stress conditions are more likely if mycorrhizal fungi and rhizosphere bacteria are present. Microbial consortia can aid both processes, phytoextraction and phytostabilization. Thus, the inoculation needs to be tested for every substrate, plant, and microbial consortium before a decision on the optimal combination can be made (Haslmayr et al. 2014). In addition, it may be advisable to improve the $\mathrm{C}_{\text {org }}$ content and lower bioavailable fractions of metals by adding compost to a very toxic substrate. This will be true specifically for tailings or for heaps with high concentrations of mobile fractions of metals. In contrast to conventional methods of covering a heap to exclude water and air entrance, here, only a 5 - to 10 -cm layer is mixed in with the upper 15 to $30 \mathrm{~cm}$ of heap or tailing material. In addition to improving the structure of the substrate and aiding plant nutrition, the compost will also contain a vivid microbial community. However, since this community is not adapted to the harsh conditions at the former mining site, only few of the microbes will survive. Thus, addition of microbes derived from the site still is vital for the success of such a strategy.

The impact of microbes on the $\mathrm{pH} / \mathrm{Eh}$ and therefore on the formation (and weathering) of minerals cannot be overestimated. Since metals are mobile under certain physicochemical conditions, the alterations of geochemical parameters by microbial activities modify metal mobility, fractionation patterns, and mineral composition (Allard et al. 2014). Here, again, one can learn from the examples of AMD sites. Biomineral formation has been reported, for example, in the waters coming from galleries of a historic zinc mine in Sardinia, Italy (Podda et al. 2014). Here, hydrozincite is formed in the creek. One of the main aspects of hydrozincite biomineralization is its effectiveness in the abatement of bioavailable heavy metals. In addition to zinc removal, lead is coprecipitated with hydrozincite and/or retained onto the hydrozincite surfaces as an inner sphere complex. Thus, hydrozincite can be regarded as an effective trap for lead, while cadmium can be easily washed out. At the former uranium mining site in Ronneburg, Germany, iron and manganese (hydro)oxide biogeogenic barriers have been formed in the substrate added after removal of a leaching heap during the past 20 years. Rare earth elements, as well as other metals co-occurring at the site, are co-precipitated with these cemented layers. Hence, the formation of (hydro)oxides can act to remove iron and manganese as well as other metals from the groundwater passing the barrier. Hence, the precipitates not only serve the purpose of remediation of AMD, but at the same time will be a source of future, or even contemporary, metal mining.
Taken together, from all parts assembled above, we can develop a generalized view on AMD sites. In such a scenario, AMD is generated within the (closed) mine and from heaps or tailings. This water is entering creeks as surface water or produces return flow. The surface of stabilized tailings, as well as soil on heaps or places of former heaps with high metal loads, will impact newly added topsoil through capillary rise, and windblown particulate matter as well as washed-out particles are providing a challenge for formerly uncontaminated soils and ecosystems. The AMD runoff might settle in ponds. In addition, the groundwater is contaminated, and here, the use for drinking water supply is not possible for ages. Therefore, further increasing the metal loads in groundwater should be minimized if at all possible. The single parameters need to be tested not only in laboratory or greenhouse experiments, but necessarily also under natural conditions in field trials (Sprocati et al. 2014a).

To use biologically aided techniques for remediation actions (Fig. 1), we could use this scenario to put the measures discussed above into perspective. A collaborative research like the project UMBRELLA (Using MicroBes for the regulation of heavy metaL mobiLity at ecosystem and landscape scAle) covered in this special issue is necessary to develop integrated measures for bioremediation approaches to AMDinfluenced areas. The project UMBRELLA was funded by the EU within framework 7 to identify processes applicable to other sites across Europe, spanning different climatic regions and different contaminations. Modeling the processes of redistribution of metals (Gamarra et al. 2014) will be needed to adopt the optimized strategy for every single site. But, as can be seen from the original research articles, plentiful tools are available if biological and (hydro)geological research is combined with modeling and end users to provide toolboxes for the cost-effective bioremediation of large sites affected by heavy metals.

Acknowledgments We would like to thank Anja Grawunder for providing the drawing in this article and the entire team involved in the EU project UMBRELLA for productive and very friendly cooperation. Financial support is acknowledged from EU (UMBRELLA project), BMBF (Strahlung und Umwelt), and DFG (GRK 1257 and JSMC). We wish to thank ESPR for the opportunity to present the results of this collaborative research and for the invitation to this special issue.

\section{References}

Allard B, Bäckström M, Karlsson S, Grawunder A (2014) Neutralisation of an acidic pit lake by alkaline waste products. Environ Sci Pollut Res. doi:10.1007/s11356-013-2026-x

Baumann N, Arnold T, Haferburg G (2014) Uranium contents in plants and mushrooms grown on a uranium-contaminated site near Ronneburg in Eastern Thuringia/Germany. Environ Sci Pollut Res. doi:10.1007/s11356-013-1913-5

Gamarra JGP, Brewer PA, Macklin MG, Martin K (2014) Modelling remediation scenarios in historical mining catchments. Environ Sci Pollut Res. doi:10.1007/s11356-013-2170-3 
Grawunder A, Merten D, Büchel G (2014) Origin of middle rare earth element enrichment in acid mine drainage-impacted areas. Environ Sci Pollut Res. doi:10.1007/s11356-013-2107-x

Haslmayr H-P, Meißner S, Langella F, Baumgarten A, Geletneky J (2014) Establishing best practice for microbially aided phytoremediation. Environ Sci Pollut Res. doi:10.1007/s11356-013-2195-7

Langella F, Grawunder A, Stark R, Weist A, Merten D, Haferburg G, Büchel G, Kothe E (2014) Microbially assisted phytoremediation approaches for two multi-element contaminated sites. Environ Sci Pollut Res. doi:10.1007/s11356-013-2165-0

Medas D, Lattanzi P, Podda F, Meneghini C, Trapananti A, Sprocati A, Casu MA, Musu E, De Giudici G (2014) The amorphous Zn biomineralization at Naracauli stream, Sardinia: electron microscopy and X-ray absorption spectroscopy. Environ Sci Pollut Res. doi: 10.1007/s11356-013-1886-4

Neagoe S, Stancu P, Nicoară A, Onete M, Bodescu F, Gheorghe R, Iordache V (2014) Effects of arbuscular mycorrhizal fungi on Agrostis capillaris grown on amended mine tailing substrate at pot, lysimeter, and field plot scales. Environ Sci Pollut Res. doi: 10.1007/s11356-013-1908-2

Nicoară A, Neagoe A, Stancu P, de Giudici G, Langella F, Sprocati AR, Iordache V, Kothe E (2014) Coupled pot and lysimeter experiments assessing plant performance in microbially assisted phytoremediation. Environ Sci Pollut Res. doi:10.1007/s11356013-2489-9

Pérez Rodríguez N, Langella F, Rodushkin I, Engström E, Kothe E, Alakangas L, Öhlander B (2014) The role of bacterial consortium and organic amendment in $\mathrm{Cu}$ and $\mathrm{Fe}$ isotope fractionation in plants on a polluted mine site. Environ Sci Pollut Res. doi:10.1007/s11356013-2156-1

Podda F, Medas D, De Giudici G, Ryszka P, Wolowski K, Turnau K (2014) Zn biomineralization processes and microbial biofilm in a metal-rich stream (Naracauli, Sardinia). Environ Sci Pollut Res. doi: 10.1007/s11356-013-1987-0

Rull F, Guerrero J, Venegas G, Gázquez F, Medina J (2014) Spectroscopic Raman study of sulphate precipitation sequence in Rio Tinto mining district (SW Spain). Environ Sci Pollut Res. doi: 10.1007/s11356-013-1927-Z

Sjöberg V, Karlsson S, Grandin A, Allard B (2014) Conditioning sulfidic mine waste for growth of Agrostis capillaris - impact on solution chemistry. Environ Sci Pollut Res. doi:10.1007/s11356-014-2600-x

Sprocati AR, Alisi C, Pinto V, Montereali MR, Marconi P, Tasso F, Turnau K, De Giudici G, Goralska K, Bevilacqua M, Marini F, Cremisini C (2014a) Assessment of the applicability of a "toolbox" designed for microbially assisted phytoremediation: the case study at Ingurtosu mining site (Italy). Environ Sci Pollut Res. doi:10.1007/ s11356-013-2154-3

Sprocati AR, Alisi C, Tasso F, Fiore A, Marconi P, Langella F, Haferburg G, Nicoara A, Neagoe A, Kothe E (2014b) Bioprospecting at former mining sites across Europe: microbial and functional diversity in soils. Environ Sci Pollut Res. doi:10.1007/s11356-013-1907-3

Wernitznig S, Adlassnig W, Sprocati AR, Turnau K, Neagoe A, Alisi C, Sassmann S, Nicoara A, Pinto V, Cremisini C, Lichtscheidl I (2014) Plant growth promotion by inoculation with selected bacterial strains versus mineral soil supplements. Environ Sci Pollut Res. doi:10.1007/s11356-013-1928-y

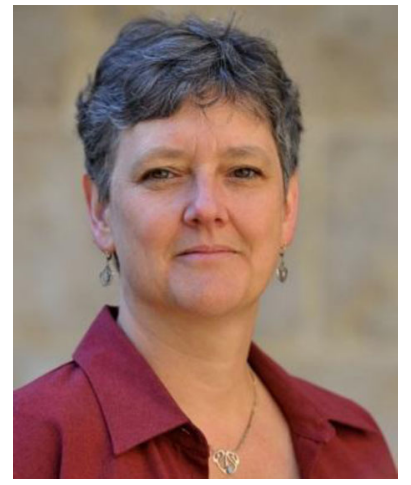

Prof. Dr. Erika Kothe currently is Vice-Rector of the Friedrich Schiller University Jena, Germany. She holds a chair for Microbial Communication at the Institute of Microbiology. Her research interests are in fungal genetics, where signal exchange and pheromone response are studied with the model basidiomycete Schizophyllum commune, in the mutual symbiosis of ectomycorrhiza with special emphasis on host-fungus interactions and in bio-geo interactions, which encompasses research on heavy metal resistance in streptomycete bacteria. The effects of heavy metal resistant strains on metal mobility and plant growth promotion are specifically included in this research topic. A test field site for inoculation with selected strains was established in 2004, and there the impact of, specifically, streptomycetes on heavy metal uptake into plants or metal mobility with the percolating water is studied. She was coordinator of the 17 partner project UMBRELLA funded through the EU-FP7 program that is featured in this special issue.

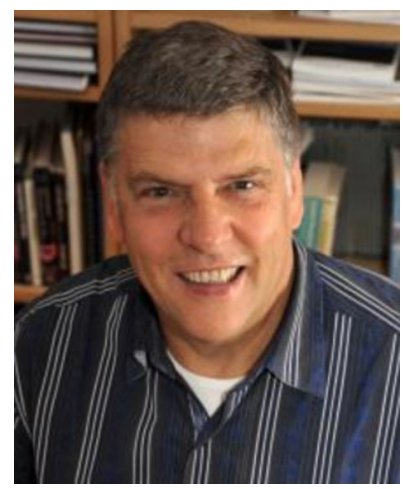

Prof. Dr. Georg Büchel holds a chair for Applied Geology at the Institute of Geosciences of the Friedrich Schiller University Jena, Germany. His research topics are Maar lakes in different climatic zones, from the tropics with a long standing research project in Java, to the German Maar district Eifel and to the Ukinrek Maar in Alaska. Together with Prof. Kothe he established a new study program for $\mathrm{BSc} / \mathrm{MSc}$ Biogeosciences at the Friedrich Schiller University Jena. This is related to his research topic of bio-geo interactions with a focus on reactive transport of metals. For that, a test field site in the former uranium mining site near Jena was established which serves to study the processes in metal transport in the environment and into plant biomass. Specifically the formation of reactive (bio)geological barriers, manganese and iron oxide formation and dissolution, and the potential of rare earth elements to follow reactive transport through fractionation patters are the major research fields. He was cocoordinator of the 17 partner project UMBRELLA funded through the EU-FP7 program that is featured in this special issue. 